\title{
Exploring the Extrinsic and Intrinsic Motivations in Blogging: A Survey on Hong Kong
}

\section{University Students}

\author{
Ying LI, City University of Hong Kong, Hong Kong \& Gongcheng LIN, Sun Yat-Sen \\ University, China
}

\begin{abstract}
Blogging stickiness and motivations have become a frequently studied topic in blogging research for several years. Yet few research pay attention to the difference between the initial motivation and current motivations. This study proposes to investigate and understand bloggers behaviors through specifying the intrinsic and extrinsic components of their motivations. Two major questions were raised and explored in this study: 1 . what the reasons that promote students to initiate blogs are; 2. how the blogging motivations and behavior patterns interact in blog maintaining. Based on a survey of 186 bloggers among City University of Hong Kong, it is found that: three major motivations (practicing a new type of diary, curiosity and thoughts on following the crowd) are the most important motivations in initiating blogging. In maintaining a blog, the hypothesis that social connection motivation is positively related to interaction-oriented behavior while emotion pouring motivation is positively related to self-restriction behavior in expression is supported.
\end{abstract}

Keywords: Blogging, motivations, blogging behavior 
Primitive studies on blogging were more like commentary or summary on the trend based on personal observation and experiences since they were mostly authored by media or IT practitioners (Jin, 2007). Main focus of blog study is the functional aspects of blog and the social implication it brings to the media (Chou, 2005); limited effort have been put on the producer side, which may actually compose a fundamental component of studying blogging.

Earlier studies on why people blog mostly treated reasons for starting blogging and motivations of stickiness to blogging as a whole, with exploratory approaches mostly adopted. An important study was carried out by Efimova (2003) who used her own blog as a platform of data collection to analyze "the stickiness factor" of blogs. Efimova figured out that curiosity, improving personal learning and interest in communication are most frequently quoted as reasons to start blogging. As for stickiness factors, Efimova concluded that personality and technology convenience enabled adoption of blog most. In 2004, Veigas conducted a study of blogging behavior and found that most blogs $(83 \%)$ were "personal ramblings" in nature, a feature still characterizes the blogosphere today. Also in 2004, Nardi, Schiano, Gumbrecht, and Swartz examined the motivation of blogging in depth. As an exploratory study, they adopted ethnographic interviews and summed up five blogging motivations: "to document life experiences, to provide commentary and opinions, to express deeply felt emotions, to articulate ideas through writing, and to form and maintain community forums." This study has been widely consulted by later studies. Although divergent rationales for the reasons and motivations for blogging have been provided, quite a number of the reasons are actually overlapping.

Later research on blogging motivations began to integrate social psychology theories or frameworks into investigating deep incentives underlying bloggers' behavior based on the earlier descriptions of motivations or behavior, raising a series of elementary models for further study. In 2006, Brady proposed a positive feedback system framework bridging reading and posting behavior together in analyzing blogging and found that positive feedback 
from readers was a fundamental motivation promoting bloggers to stick to blogging. Brady also suggested that reasons to begin blogging are often different from the eventual motivations they have to continue to blog but he didn't offer a detailed analysis on this argument. Enlightened by Nardi’s study, several Taiwanese scholars designed a survey among Taiwanese and validated a framework addressing blogger's motivations, behaviors, and management effort heterogeneity together, clarifying the relationships among them (Huang, Shen, Lin, Chang, 2007). In this model, blogging behavior was decomposed into interaction-oriented behavior and information-oriented behavior. The study validated the model proposed through testing the relationship between motivations clarified by Nardi and the behaviors pattern of blog management. In a more recent study, Liu, Liao and Zeng (2007) addressed expectancy theory into analyzing motivations for blogging, figuring out that rewards played an important role in motivating bloggers. Bloggers in their study ranked pouring out feelings and connecting with people respectively as their two most valued rewards; those bloggers with high motivation for rewards have higher level of blogging intention and are willing to spend more time on maintaining their blog.

Generally speaking, research on blogging motivation started from exploration with qualitative methods or descriptive survey roughly probing into the motivations and gradually proceeded to establishing relationships between motivations and behaviors including blogging and other online activities. In this procedure, main efforts were put into measuring different sublevels of motivation yet the behavior dimension was primarily measured by energy or time spent on it.

This study argues that blogging is a multi-dimensional behavior corresponding to multi motivations since bloggers' behavior is not homogeneous and even the same blogger may behave differently based on various motivations. With the advantages of anonymity brought by Internet, people may bring quite a lot of goals which are oftentimes difficult to obtain in real life: tension may be released through pouring out feelings in blogs and at the same time, social network may be maintained or expanded in the same sphere. Despite of that advantage, 
it is possible that attention from readers may bring potential trouble to the bloggers. Consequence, many bloggers may be cautious in content generating and may even self-censor their blogs before posting the article. Thus bloggers may behave under the dual motivations of both satisfying extrinsic need and the need of protecting privacy and safety. This phenomenon might be more common among youth as they are still experiencing identity formation and have relatively less ability or power in coping with contingencies. This study proposes to examine the relation between young bloggers' motivation and behavior under the proposed framework of the dual motivation as an exploratory investigation for further studying the complicated behavior patterns and underlying motivations.

\section{Research Question and Hypotheses}

This study proposes to understand young generation's blogging behavior based on two general motivations: extrinsic motivation and intrinsic motivation. The distinction between the two motivations has been asserted by cognitive psychologists that intrinsic motivation usually leads to engaging in an activity for the sake of the inherently interesting or satisfying process whereas extrinsic motivation is oftentimes related with the reinforcement of the rewards or the potential value of the outcomes (Ryan \& Deci, 2000). Extrinsic motivation in this study is defined as the social-oriented motivations in search of satisfaction from exterior social environments. For young people, extrinsic motivation mainly refers to connection with friends or fame-seeking. Intrinsic motivation basically indicates that bloggers blog for their inherent satisfaction or four pouring private emotions rather than external rewards. On behavioral level, it is proposed that bloggers tend to behave based on weighing the psychological rewards corresponding to the intrinsic and extrinsic motivation.

Before exploring motivations underlying maintenance behaviors, this study firstly asks a general question: why students start to blog? As for why students keep blogging, several assumptions are proposed on testing relationships between motivations and behaviors: (a) bloggers are more likely to be driven by intrinsic motivation when they initiate blogs; (b) in maintaining blogging, bloggers will be motivated by an integration of the two types of 
motivations; (c) in order to achieve best psychological and social rewards, bloggers will create more opportunities to facilitate extrinsic motivation and (d) bloggers consciously restrict their blog content so that they will release intrinsic motivations safely.

The proposed model drawn from assumptions discussed above is presented in figure 1.

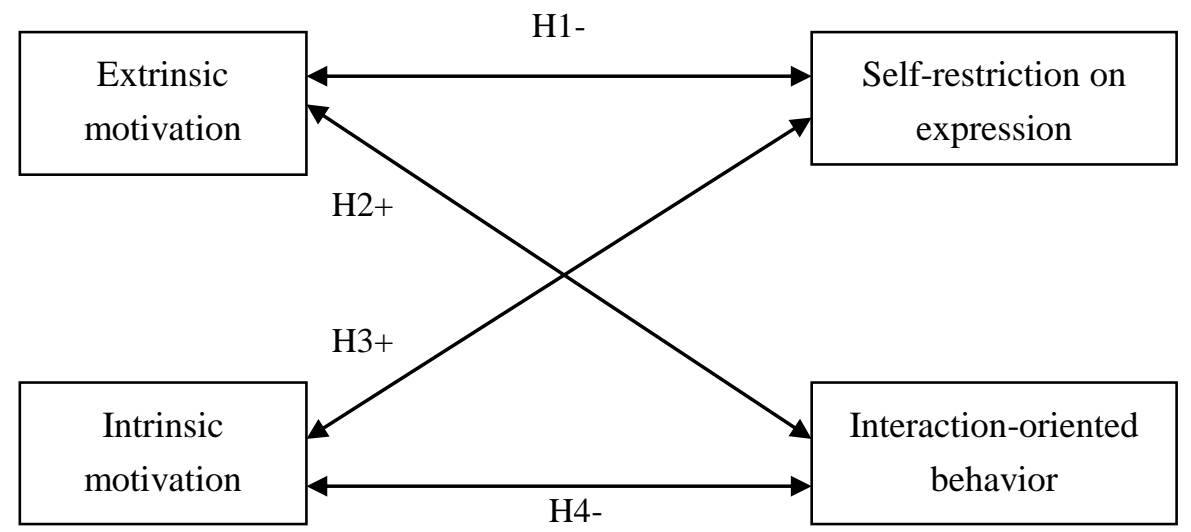

Figure 1. Proposed model of this study

Based on the framework, the more specific hypotheses are as follows:

H1: Extrinsic motivation is negatively related to self-restriction on expression, such that the more blogging is motivated by extrinsic motivation, the less possible that the author will restrict their expression in blog.

$H 2$ : Extrinsic motivation is positively related to interaction-oriented behavior. Such that the more blogging is motivated by extrinsic motivation, the more likely they will pay attention to affiliating to online social interaction involved in blogosphere.

H3: Intrinsic motivation is positively related to self-restriction on expression. Such that the more the blogger tend to satisfy their intrinsic motivation in blog, the more restriction they will put on expression and be more cautious in expression.

H4: Intrinsic motivation is negatively related to interaction-oriented behavior. Such that the more the blogger tend to satisfy their intrinsic motivation in blog, the less they less likely they will pay attention to affiliating to online social interaction involved in blogosphere. 


\section{Methods}

\section{Survey design}

A paper survey was utilized in this study targeting at individual students in City University of Hong Kong who maintain their personal blog. According to a telephone survey conducted by Pew Internet\& American Life Project, more than half of the bloggers (those who own their own blogs) are under the age of 30, similar findings were also reported by Technorati, the 2008 worldwide blogger survey figured out that among the Asian survey subjects, 69\% are college graduate and 73\% are 18-34 years old (Technorati, 2009). Therefore, university students compose a typical group of bloggers not only for the research purpose of this study, but also may be useful for other studies.

400 copies of the questionnaires were distributed among students selected through stratified sampling framework regarding class time and classroom location in April, 2009. To alleviate privacy concerns, no identifying information was tracked or requested of the respondents. Responses from the survey were compiled into a SPSS file and analyzed.

\section{Survey Description and Measurement Construction}

The blogger background section concerns with basic information of bloggers such as gender, age, home region, educational background and student status in university. Motivation and behavior was evaluated by 5-point Likert scales, with 1 being "strongly disagree" and 5 being "strongly agree". Updating conduct was indicated by the number of articles posted and time spent on wring each article.

Since the measurements in this study are largely established on a mix of items adopted in other surveys and items designed by the researcher of this study, it is necessary to validate them before being further analyzed. In the initial measurements, there are altogether 6 items assigned to the construct of motivation and 6 items assigned to behavior. This study began with the exploratory factor analysis as the first step to validate the measurements. After two rounds of analyses, for each construct, 5 items survived and 2 factors emerged. Result is 
shown in Table 1 and Table 2. Compared to initial measurements, the most salient differences between before and after factor analysis are (a) emotion pouring scale became a single-item scale and (b) originality was excluded in construction of behavior. The two factors for motivation construction altogether explained $58.93 \%$ of the total variance while the two factors for behavior construction altogether explained $56.52 \%$ of the total variance.

Table 1. Factor analysis for motivation items

\begin{tabular}{|c|c|c|}
\hline \multirow{2}{*}{ Motivation Items } & \multicolumn{2}{|l|}{ Component } \\
\hline & Social connection & Emotion release \\
\hline $\begin{array}{l}\text { Gaining support on my viewpoint } \\
\text { from others }\end{array}$ & .745 & \\
\hline $\begin{array}{l}\text { Communicating with other } \\
\text { bloggers }\end{array}$ & .721 & \\
\hline Becoming a focus person & .659 & \\
\hline Sharing my materials & .615 & \\
\hline Pouring out my thoughts/emotion & & .958 \\
\hline
\end{tabular}

Table 2. Factor analysis for behavior items

\begin{tabular}{|l|l|l|}
\hline \multirow{2}{*}{ Behavior Items } & Component \\
\cline { 2 - 3 } & Self-restriction on expression & Interaction-oriented behavior \\
\hline Limited expression & .788 & \\
\hline $\begin{array}{l}\text { Unwillingness of sharing } \\
\text { blog }\end{array}$ & .788 & \\
\hline $\begin{array}{l}\text { Linking } \\
\text { to blogosphere }\end{array}$ & .796 \\
\hline Showing more linkage & & .675 \\
\hline $\begin{array}{l}\text { Attention to others' } \\
\text { reaction }\end{array}$ & .521 \\
\hline
\end{tabular}

Secondly, the reliability of each scale was tested. Result is shown in Table 3. Cronbach's $\alpha$ coefficients of the two factors for behavior construction are .40 and .45 , which could be marginally accepted. Reliability of behavior construction was not very high, indicating that the scales need to be improved in further studies. 
Table 3. Result of reliability testing

\begin{tabular}{|l|l|l|l|l|}
\hline \multicolumn{2}{|l|}{} & \multicolumn{2}{l|}{ Motivation } & \multicolumn{2}{l|}{ Behavior } \\
\cline { 2 - 5 } & $\begin{array}{l}\text { Social } \\
\text { connection }\end{array}$ & $\begin{array}{l}\text { Emotion } \\
\text { release }\end{array}$ & $\begin{array}{l}\text { Self-restricted } \\
\text { expression }\end{array}$ & $\begin{array}{l}\text { Social-interaction } \\
\text { oriented behavior }\end{array}$ \\
\hline Cronbach's $\alpha$ & .63 & $1.00^{\mathrm{a}}$ & .40 & .45 \\
\hline
\end{tabular}

Note:

a. single item scale

\section{Results}

\section{Description of Participants}

From the 400 questionnaires distributed, a total of 247 responses were returned. Finally, 61 responses in the 247 were eliminated from the analysis because the respondents: (a) indicated they did not have their own blogs $(n=59)$ or $(b)$ assigned same scores on each of the items under the same measurement in the questionnaire $(n=2)$.

Among the 186 effective responses, female students were a little more on the number than male students, with $52 \%$ identifying themselves as female and $48 \%$ identified as male. $94 \%$ of respondents were between the ages of $18-25$, with $61 \%$ identifying themselves as $18-21$ years of age and 33\% identifying themselves as 22-25 years of age. Survey participants were mostly Hong Kong local residents $(90 \%, n=166)$, with the next highest group being $9 \%$ participants who identified as mainland Chinese. Only $1 \%$ of the participants were oversea students. As for the education status, $90.66 \%$ are pursuing Bachelor degree or below, with $36.81 \%$ of them sub-degree students and $53.85 \%$ are undergraduate students. $73.08 \%$ of the respondents got University granted committee funding while $26.92 \%$ are self-financed. $95.6 \%$ of the respondents are full-time students. Demographical distributions of the sample are presented in Table 4. In a whole, the sample could represent Hong Kong university student group. 
Table 4. Description of survey participants

\begin{tabular}{|c|c|c|c|}
\hline Blogger Background Item & No. Participants & Percentage of Total & $\begin{array}{l}\text { Valid } \\
\text { percentage }\end{array}$ \\
\hline \multicolumn{4}{|l|}{ Gender } \\
\hline Female & 95 & $51.1 \%$ & $51.9 \%$ \\
\hline Male & 88 & $47.3 \%$ & $48.1 \%$ \\
\hline No response & 3 & $1.6 \%$ & \\
\hline \multicolumn{4}{|l|}{ Age range } \\
\hline$<=17$ years & 1 & $0.5 \%$ & $0.5 \%$ \\
\hline $18-21$ years & 112 & $60.2 \%$ & $61.2 \%$ \\
\hline $22-25$ years & 60 & $32.3 \%$ & $32.8 \%$ \\
\hline 26-29 years & 3 & $1.6 \%$ & $1.6 \%$ \\
\hline$>=33$ years & 7 & $3.8 \%$ & $3.8 \%$ \\
\hline No response & 3 & $1.6 \%$ & \\
\hline \multicolumn{4}{|l|}{ Home region } \\
\hline $\begin{array}{l}\text { Hong Kong permanent } \\
\text { Residents }\end{array}$ & 166 & $89.2 \%$ & $90.2 \%$ \\
\hline $\begin{array}{ll}\text { Mainland } & \text { Chinese } \\
\text { Residents } & \\
\end{array}$ & 17 & $9.1 \%$ & $9.2 \%$ \\
\hline Oversea Residents & 1 & $0.5 \%$ & $0.5 \%$ \\
\hline No response & 2 & $1.1 \%$ & \\
\hline \multicolumn{4}{|l|}{ Education background } \\
\hline Sub-degree students & 67 & $36.0 \%$ & $36.8 \%$ \\
\hline Undergraduates & 98 & $52.7 \%$ & $53.8 \%$ \\
\hline
\end{tabular}




\begin{tabular}{|l|l|l|l|}
\hline Taught post graduates & 11 & $5.9 \%$ & $6.0 \%$ \\
\hline Research post graduates & 6 & $3.2 \%$ & $3.3 \%$ \\
\hline No response & 4 & $2.2 \%$ & \\
\hline
\end{tabular}

\section{Blog Usage}

As illustrated in figure 2, a remarkable majority of the respondents $(83.78 \%)$ has maintained their blogs for more than one year with $43.78 \%$ of them $(n=81)$ indicating they had maintained their blogs for $1-3$ years and $40.00 \%(n=74)$ with more than 3 years. Only 30 of the 186 respondents had not more than 1 year's blogging experience.

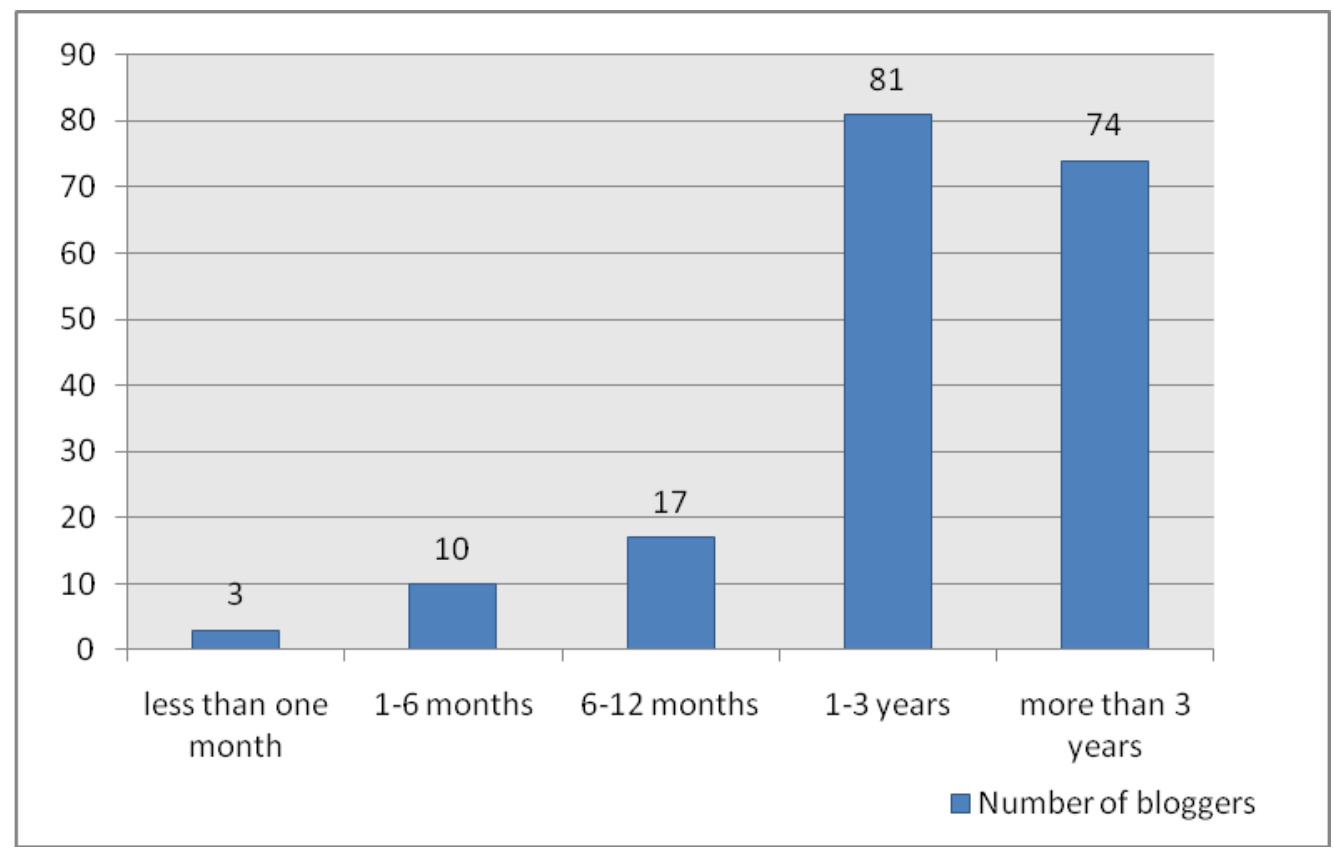

Figure 2. Reported time length of blogs that had been maintained, from the day it was initiated

As shown in figure 3, nearly two thirds of the respondents indicated that they had updated their blogs last month. Among them, 52.15\% (n=97) updated 1-7 times and 12.90\% are even more active. There are still $34.95 \%(n=65)$ of the respondents reported that they didn't update their blog. 


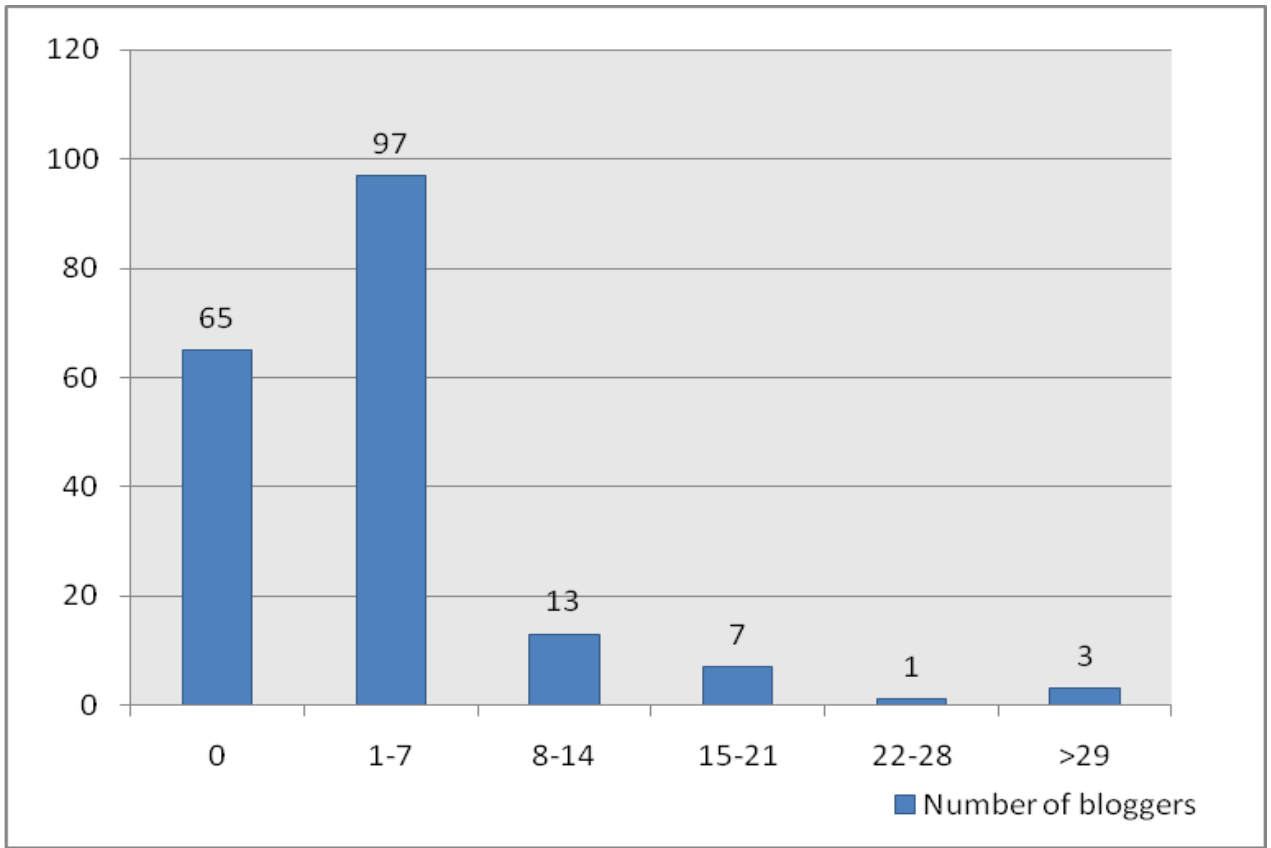

Figure 3. Reported frequency of updating blog in last month.

As for the average time length for a single piece of blog article, most of the respondents spent not more than one hour. $61.08 \%(n=113)$ of the respondents write one article within 30 minutes while it cost 30 minutes to 1 hour for another $30.27 \%$ (56) to write a piece of blog article.

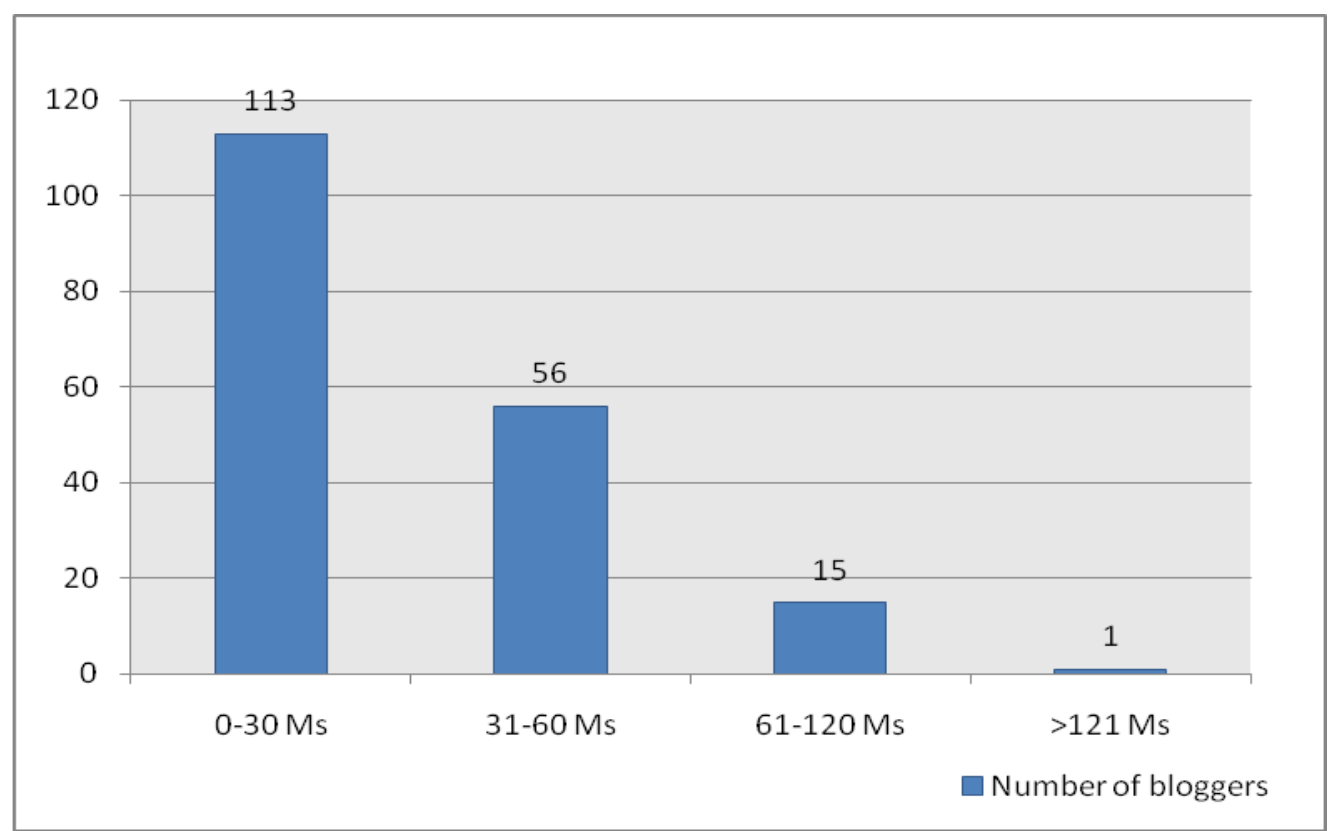

Figure 4. Reported time lengths on one piece of blog

To sum up, the majority of the respondents are experienced blogger; most respondents are 
active users who frequently updated their blogs last month. The main body of the respondents spent limited time on each article. The usage pattern implied that blogging may firmly exist as part of the respondents' daily life.

\section{Why Bloggers Start a Blog}

As shown in Table 5, when asked to select main reasons for initiating a blog, the highest percentage $(34.7 \%)$ of responses indicated that the main reason was documenting everyday feelings. Other reasons endorsed most were following the Crowd (16.6\%), expressing opinion (14.5\%), and storing material (10.0\%). Less emphasis was put on social interaction oriented reasons; for others' invitations, sharing materials, making more friends and for fame together composed $20.5 \%$ of selection. A notable reason reflecting influence of others is following the crowd; however, this factor also implies that bloggers may be promoted by curiosity.

Table 5. Reasons of Initiating a Blog

\begin{tabular}{|l|l|l|}
\hline \multirow{2}{*}{ Reasons } & responses & Percentage \\
\cline { 2 - 3 } Documenting everyday feelings & 132 & $34.7 \%$ \\
\hline Following the flow & 63 & $16.6 \%$ \\
\hline Expressing opinions & 55 & $14.5 \%$ \\
\hline Storing materials & 38 & $10.0 \%$ \\
\hline For others' invitations & 35 & $9.2 \%$ \\
\hline Sharing materials & 29 & $7.6 \%$ \\
\hline Making more friends & 11 & $2.9 \%$ \\
\hline Other reasons & 9 & $2.4 \%$ \\
\hline Assisting study or work & 5 & $1.3 \%$ \\
\hline For fame & 3 & $0.8 \%$ \\
\hline
\end{tabular}




\section{How bloggers maintain blogs: relationship between motivation and behavior}

Bloggers evaluated the 5 motivations of blogging and 5 behavior characteristics. Highest mean score was found on pouring out thoughts/emotion while lowest mean score was on using blog to become a focus person. Other items obtained relatively medium scores. Mean scores for each item and factors were presented in Table 6, Table 7 and Table 8.

Table 6. Evaluations of Items

\begin{tabular}{|l|l|l|}
\hline Motivation Items & Mean & Std. Deviation \\
\hline $\begin{array}{l}\text { Gaining support on viewpoint } \\
\text { form others }\end{array}$ & 3.03 & 1.15 \\
\hline $\begin{array}{l}\text { Communicating with other } \\
\text { bloggers }\end{array}$ & 2.66 & 1.18 \\
\hline $\begin{array}{l}\text { Using blogs to become a focus } \\
\text { person }\end{array}$ & 1.72 & 0.90 \\
\hline $\begin{array}{l}\text { sharing materials } \\
\text { Pouring out thoughts/emotion }\end{array}$ & 3.05 & 1.10 \\
\hline $\begin{array}{l}\text { Behavior Items } \\
\text { I'm unwilling to share my blog to } \\
\text { those who are not familiar to me }\end{array}$ & 3.08 & 0.91 \\
\hline $\begin{array}{l}\text { If there is more attention, I will } \\
\text { spend more energy on writing } \\
\text { blog }\end{array}$ & 3.32 & Std. Deviation \\
\hline $\begin{array}{l}\text { I would like to express my } \\
\text { thoughts restrictedly }\end{array}$ & 3.17 & 1.24 \\
\hline $\begin{array}{l}\text { I would like to show more linkage } \\
\text { in my blog }\end{array}$ & 2.68 & 1.07 \\
\hline $\begin{array}{l}\text { I would like to link my blog to } \\
\text { blogospheres }\end{array}$ & 2.75 & 1.06 \\
\hline
\end{tabular}

Table 7. Evaluation for Motivation Factors

\begin{tabular}{|l|l|l|}
\hline Motivation factors & Mean & Std. Deviation \\
\hline Social connection & 2.61 & 0.75 \\
\hline
\end{tabular}




\begin{tabular}{|l|l|l}
\hline Life documenting & 3.14 & 0.63 \\
\hline
\end{tabular}

Table 8. Evaluation for Behavior Factors

\begin{tabular}{|l|l|l|}
\hline Motivation Items & Mean & Std. Deviation \\
\hline Self-restriction on expression & 2.35 & 0.78 \\
\hline Interaction-oriented behavior & 2.89 & 0.73 \\
\hline
\end{tabular}

Relationships between motivations and behaviors were tested by partial correlations; controlling gender, age, blogging experience, as well as other determinants. Main findings of the study are shown in Table 9.

Table 9. Result of Model Testing

\begin{tabular}{|l|l|l|l|l|l|}
\hline & \multicolumn{3}{|l|}{ Self-restriction on expression } & \multicolumn{2}{l|}{ Interaction-oriented behavior } \\
\hline & $\begin{array}{l}\text { Partial correlation } \\
\text { coefficient }\end{array}$ & $\mathrm{p}$ & $\begin{array}{l}\text { Partial } \\
\text { coefficient }\end{array}$ & $\mathrm{p}$ \\
\hline $\begin{array}{l}\text { Social } \\
\text { connection }\end{array}$ & -.013 & .865 & .544 & .000 \\
\hline $\begin{array}{l}\text { Emotion } \\
\text { pouring }\end{array}$ & .170 & .025 & .094 & .218 \\
\hline
\end{tabular}

More specifically, this study found following findings:

1. Social connection motivation is significantly positively related to interaction-oriented behavior, such that the higher blogging is deemed to increase social connection, the more interaction the blogger will tend to exhibit in blogging. Therefore, hypothesis 2 is supported.

2. Emotion pouring motivation is positively related to self-restriction on expression, so that the more the blogger tend to pour their emotion in blog, the more restriction they will put on expression and be more cautious in expression. Therefore, hypothesis 3 is supported.

3. Social connection motivation is not significantly related to self-restriction. Hypothesis 1 is rejected. 
4. Emotion pouring motivation is not significantly related to Interaction-oriented behavior; hence, hypothesis 4 is rejected.

For further investigation, this study also found that gender has significant effect on blogging behavior. Female students were found to put more self-restriction on expression in blogging $(r=-.162, p<.05)$. It is also found in females that, emotion pouring motivation is positively related to self-restriction behavior $(\mathrm{r}=.246, \mathrm{p}<.05)$, while there is no such significant relationship among that of males $(r=.082, p=.463)$.

\section{Discussion and Conclusion}

This study starts by the question of relationships between motivation and behavior pattern, which may partly help explaining the reasons of stickiness to blog and self-disclosure or self-censorship in blogging.

Among various previous studies, Nardi's classification on motivations (Nardi, etc, 2003), models raised by Huang, etc (Huang, Shen, Lin, and Chang, 2007) and questions mentioned in Jin's research on stickiness to blogging (Jin, 2007) are especially stimulating in developing the model adopted in this study. Compared to these studies, the most prominent difference involved in this study is that both the constructs of motivation and behavior are briefly divided into two sub-dimensions concerning extrinsic stimulation and intrinsic dynamic.

In terms of reasons for initiating blogs, intrinsic motivations were ranked at the front instead of extrinsic motivations. It is understandable that university students' social network is of relatively smaller size comparing with people of older ages; thus, practicing a new type of diary, curiosity and thoughts on following the crowd may have more influence rather than the social connection motivations in registering a new blog.

In regards of testifying the model, as shown in figure 5, only the hypothesis that social connection motivation is positively related to interaction-oriented behavior and emotion pouring motivation is positively related to self-restriction behavior are supported. These 
findings imply that: (a) social connection motivation may not be conflicting with self-restriction on expression; people may be highly involved into online social connection activities and protect their privacy or be cautious about speaking out true opinion at the same time; (b) the similar rationale may also be applicable to relationship between emotion pouring motivation and interaction-oriented behaviors since bloggers may release their tensions or talk out feelings to their intimate friends or those who are outside of the bloggers' real life circle, therefore, this motivation may also increase degree of online social interaction.

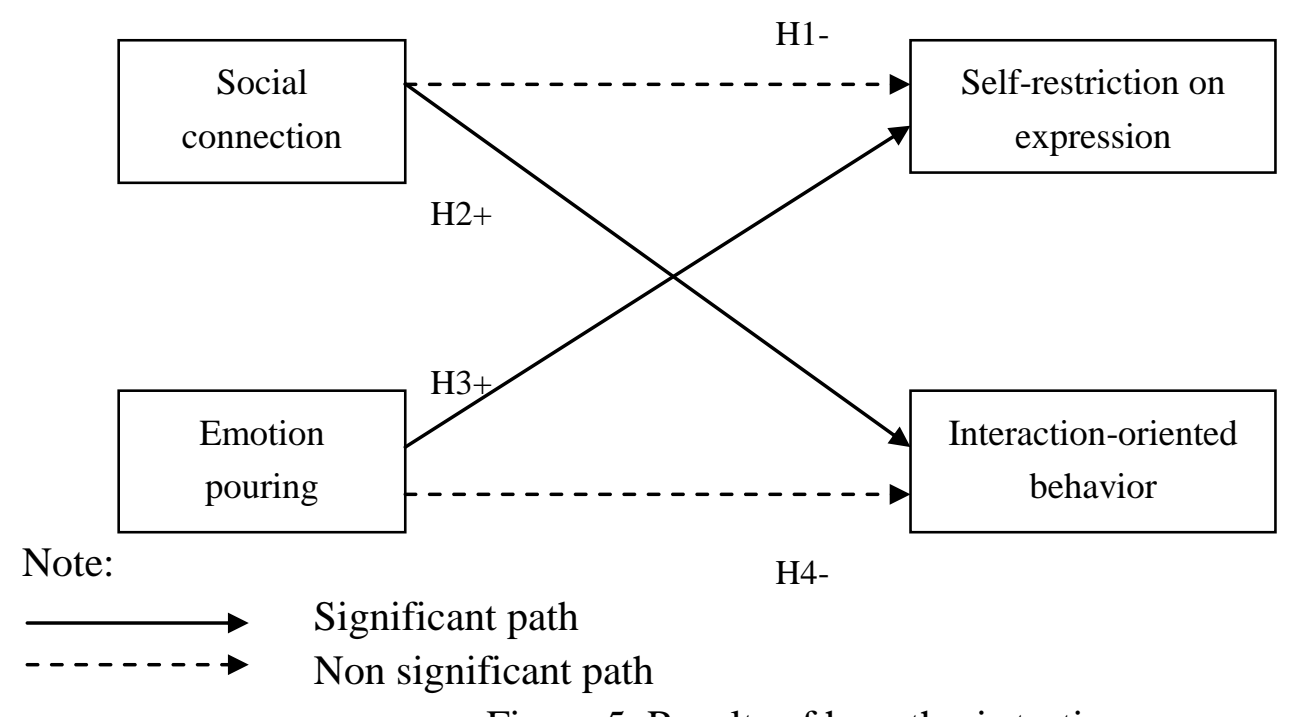

Figure 5. Results of hypothesis testing

Further more, gender has significant influence on behavior, females tends to put more self-restriction on expression. The positive relationship between emotion pouring motivation and self-restriction behavior noticed in the whole sample is largely contributed by behavior of females since there was no such significant relationship found in that of males.

Although not included in the proposed research design, a series of regressions were still conducted to predict blog usage pattern (years of blogging, update times in last month and time spent on each article). It is found that, as shown in Table 10, gender and age have larger effect on predicting blog usage pattern. Compared with males, females tend to update blogs more frequently last month and spent more time on each article. Older bloggers had longer experience of blogging and spent more time on each article. As for the motivations, only the 
motivation of communicating with other bloggers is significantly related to update times in last month, indicating that the more the bloggers are motivated by communication need, the more frequently they may update their blogs.

Table 10. Blog Usage Pattern

\begin{tabular}{|l|l|l|l|}
\hline & $\begin{array}{c}\text { Years of } \\
\text { blogging }(\beta)\end{array}$ & $\begin{array}{c}\text { Update times } \\
\text { in last month } \\
(\beta)\end{array}$ & $\begin{array}{c}\text { Time spend on } \\
\text { each article }(\beta)\end{array}$ \\
\hline Motivation items & & & \\
\hline Communicating with other bloggers & & $.163^{*}$ & \\
\hline Becoming a focus person & & & \\
\hline Sharing my materials & & & \\
\hline Document my thoughts/emotion & $.182^{*}$ & & \\
\hline $\begin{array}{l}\text { Gaining supports from others on my } \\
\text { viewpoint }\end{array}$ & & & \\
\hline Demographics & & & $-.153^{*}$ \\
\hline Gender (reference=female) & & $-.198^{* *}$ & $.223^{* *}$ \\
\hline Age & .077 & .060 & .079 \\
\hline $\mathrm{R}^{2}$ & $4.0 \%$ & $2.2 \%$ & $4.2 \%$ \\
\hline $\mathrm{Adjusted} \mathrm{R}^{2}$ & & & \\
\hline
\end{tabular}

Notes:

$\# \mathrm{p}<.1 ; * \mathrm{p}<.05$

This undesignedly extended analysis not only reveals the limitation of this study but also hints further directions in this topic. For the first thing, it confirms that the reliability and validity of the original scale need a great deal of improvement; for the second thing, the blog management is greatly affected by gender and age, suggesting that the model proposed in this study may also affected by the demographic factors; third, the categorization of the motivations and behaviors are still too rough that the intention of this study to categorize bloggers simply by the factors and items adopted in this study may be confronted with a great number of challenges. Therefore, a more specific scale needs to be addressed into analyzing blogging motivation, behavior and update management. Models concerning more moderators like personality and demographic factors might be more convincing in investigating blogging motivations and behaviors. 


\section{Reference}

Brady, M. (2006). Blogs: Motivations behind the Phenomenon. Information Communication and Society Conference, 12-14. September 2006, University of York, York, UK. Available http://www.essex.ac.uk/chimera/content/pubs/wps/CWP-2006-17-blog-motivations.pd f. Retrieved on Mar, 17, 2009.

Chou, L-H (2005). The Research of Blog User and User Behavior. Unpublished Master Thesis. Taiwan: Dept. of Information Communication, Yuan-ze University.

Efimova, L. (2003). Blogs: The stickiness factor. Available at https://doc.telin.nl/dscgi/ds.py/Get/File-34088. Retrieved on Mar, 16, 2009.

Fung, H-Y. (2006). Weblogging in Hong Kong: Motivations and Self-Disclosure. Graduation project for Master of Science in New Media, School of Journalism and Communication, The Chinese University of Hong Kong.

Huang, C-Y., Shen, Y-Z., Lin, H-X., and Chang, S-S. (2007), Bloggers' Motivations and Behaviors: A Model. Journal of Advertising Research, 47(4): 472-484.

Jin, J-B. (2007), The stickiness determinants of blogging: from the perspective of user acceptance of information technology. Conference Papers -- International Communication Association, 2007 Annual Meeting.

Lenhart, A., \& Fox ,S. (2006). Bloggers: a portrait of the Internet's news storytellers. Pew Internet \& American Life Report, July 19, 2006: Available at http://www.pewinternet.org/ /media//Files/Reports/2006/PIP\%20Bloggers\%20Report \%20July\%2019\%202006.pdf.pdf. Retrieved on Mar, 17, 2009.

Liu, S-H., Liao, H-L., and Zeng, Y-T. (2007) Why people blog: an expectancy theory analysis. Issues in Information System, 8(2):232-237.

Menchen-Trevino, E. (2005) Blogger motivations: power, pull and positive feedback. Available at http://blog.erickamenchen.net/MenchenBlogMotivations.pdf. Retrieved on April, 3, 2009.

Nardi, B. A., Schiano, D.J. , Gumbrecht, M. \& Swartz, L. (2004). Why We Blog. Communications of the ACM. 47 (12): 41-46. Available at http://technorati.com/blogging/state-of-the-blogosphere/. Retrieved on Mar 17, 2009.

Ryan, R., \& Deci, E. (2000). Intrinsic and extrinsic motivations: classic definitions and new directions. Contemporary Educational Psychology. 25(4): 54-67.

Viegas, F. (2004). Blog Survey: Expectations of Privacy and Accountability. Available at http://web.media.mit.edu/ fviegas/survey/blog/results.htm. Retrieved on April, 20. 


\section{Appendix: Key items and scales}

Reasons for initiating blogging (you could chose more than one reason)
A. Documenting everyday feelings
B. Following the flow
C. Storing materials
D. Expressing personal opinions
E. Making more friends
F. Sharing materials
G. For fame
H. For others' invitations
I. Assisting study or work
J. Other reasons

Motivations of maintaining blog (5-point scale, with 1 refers to "strongly disagree" and 5 refers to "strongly agree")
A. Becoming a focus person
B. Communicating with other bloggers
C. Pouring out thoughts/emotion
D. Assisting my study or work
E. Gaining support on my viewpoint from others
F. Sharing my materials

Behaviors (5-point scale, with 1 refers to "strongly disagree" and 5 refers to "strongly agree")
A. Unwilling to share my blog to those who are not familiar to me
B. There are more articles originated by me rather than others in my blog
C. If there is more attention, I will spend more energy on writing blog
D. I will express my thoughts restrictedly
E. I would like to show more linkage in my blog
F. I would like to link my blog to blogospheres

\section{Updating management}

1. When did you originally register the blog
A. $<1$ month
B. 1-6 months
C. 6-12 months
D. 1-3 years
E. > 3 years

2. How many times did you update your blog in last month?
A. 0
B. 1-7
C. $8-14$ 

D. $15-21$
E. $22-28$
F. 29 or more

3. How long will you spend on writing an article in your blog in average?
A. $<30$ minutes
B. 31-60 minutes
C. 61-120 minutes
D. $>120$ minutes 